\title{
14
}

\section{Accounting for private benefits in ecological restoration planning}

\author{
Maksym Polyakov and David Pannell
}

\section{Key lessons}

- Selecting an effective ecological restoration project requires information about the levels of public and private net benefits that are likely to result from project implementation.

- Environmental assets on private land in agricultural landscapes may provide benefits that are valued by the landholders. The value of these benefits could be reflected in property sale prices.

- An extra hectare of native vegetation is valued more highly by the landholders of smaller properties and by the landholders of properties with smaller areas of native vegetation.

- Accounting for the private benefits generated by native vegetation when planning and targeting ecological restoration results in substantially greater biodiversity outcomes.

\section{Introduction}

Approximately 77 per cent of Australia's land area is managed by private landholders, which makes conservation on private lands an essential part of Australia's conservation strategy. Some examples 
of conservation initiatives on private land are the BushTender in Victoria, the Environmental Stewardship Project in New South Wales and Queensland, and the Whole of Paddock Rehabilitation (WOPR) scheme run by Greening Australia. Developing cost-effective ecological restoration programs on private lands is important, and it is crucial that the drivers of landholder participation in ecological restoration programs be identified (e.g. Blackmore and Doole 2013).

In this chapter, we explore several key lessons that would allow environmental managers to design effective ecological restoration programs by aligning landholders' private benefits with the public benefits of biodiversity conservation. We do this by identifying the circumstances in which native vegetation on private lands is likely to be valued by the landholder. This knowledge can be incorporated in the planning of ecological restoration programs and targeting of ecological restoration sites.

\section{Public and private benefits}

Environmental assets in rural landscapes provide a variety of benefits, or ecosystem services, to landholders (private benefits to the owners of the land in question) and to the public (public benefits to people other than the landholder). Private benefits of native vegetation include provision of shade for livestock, recreational opportunities, and increased amenity through improved aesthetics. Examples of public benefits provided by native vegetation include the provision of habitat for biodiversity, and regulation of water flows. The optimal allocation of rural land between intensive agricultural use, such as cropland or modified pasture, and native vegetation, which has conservation, amenity, and limited production value, depends on the balance between public and private benefits generated by the native vegetation, and the costs of land use change, such as ecological restoration, including the opportunity cost of foregone agricultural production. 


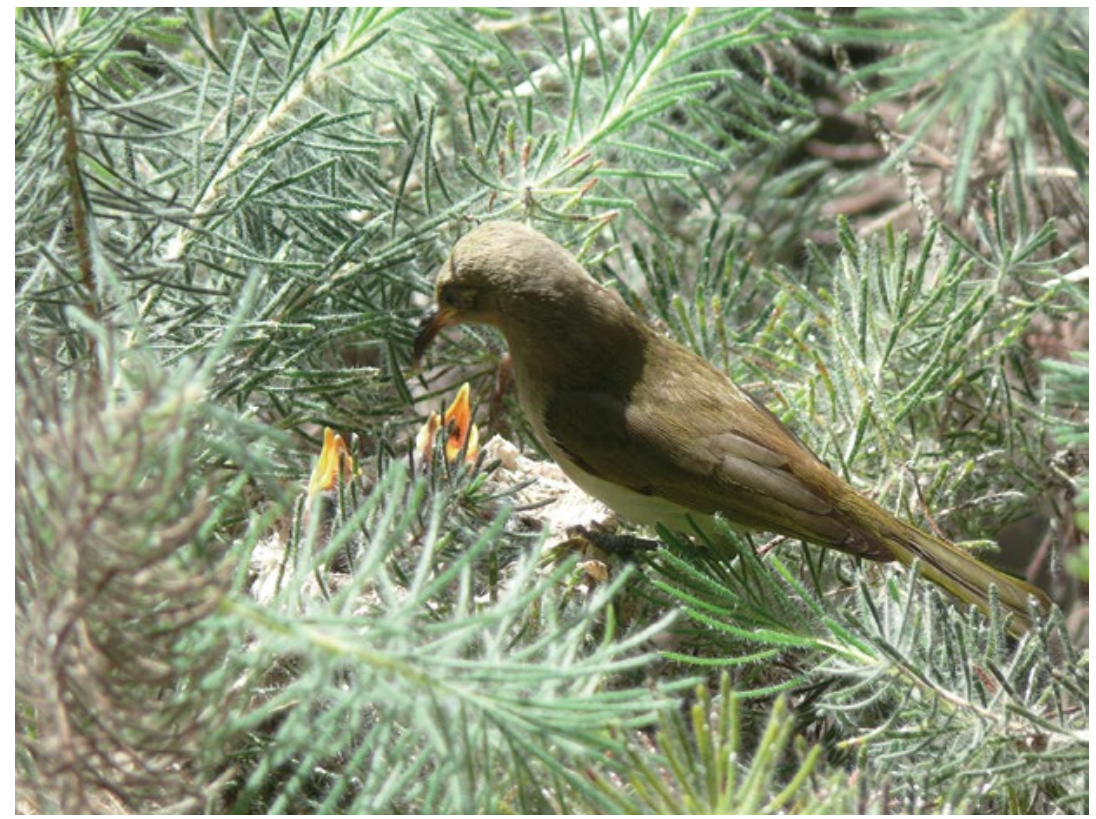

Figure 14.1: A brown honeyeater feeding its young.

Source: Photo by Maksym Polyakov.

One of the ways to increase the provision of public benefits from agricultural landscapes is to use ecological restoration to reallocate land from intensive agriculture to conservation use. Designing effective policy instruments to implement natural resource management (NRM) actions, such as ecological restoration on private lands, requires information on private benefits generated by these management actions. Pannell (2008) developed a framework to guide the choice between policy mechanisms, based on the levels of public and private net benefits likely to result from proposed management actions (see Chapter 18). The framework highlights the importance of targeting funds in environmental programs to selected spatial targeting areas, based on the likely levels of public and private net benefits. For example, selecting ecological restoration projects that provide public benefits and modest private benefits would provide high value for money, because policy mechanisms are likely to influence behaviour at relatively low public cost (Polyakov et al. 2015). 


\section{Environmental benefits valued by the landholders}

Environmental assets located on private properties, such as native vegetation, may generate private benefits that could be reflected in property values. These values can be estimated using the hedonic pricing method. While there have been many studies that value environmental assets on public lands, few studies have investigated the values of ecosystem services generated by environmental assets located on private rural lands. For example, Ma and Swinton (2011) found that environmental assets, such as forest, wetlands, and streams, located both on the property and in the surrounding landscape, increase the value of rural properties in Michigan. Walpole and Lockwood (1999) measured the effect of native vegetation on the values of rural properties in north east Victoria and southern New South Wales. While they did not find a measureable impact on property value when native vegetation covered less than 50 per cent of property area, coverage above 50 per cent decreased property value. Polyakov et al. (2013) estimated that the native vegetation on rural lifestyle properties in Victoria has a positive and diminishing marginal value, with the property value maximised when the proportion of area occupied by native vegetation is approximately 40 per cent, which increases property value by 10.5 per cent relative to the value of a similar property without native vegetation. However, when the area occupied by native vegetation exceeds 80 per cent of the property, the value of the property is reduced to less than the value associated with no native vegetation. Since the current extent of native vegetation is lower than the extent that would maximise its amenity value to many landholders (Polyakov et al. 2013), the welfare value to people living in the landscape may be improved by restoring native vegetation on cleared lands.

These examples demonstrate that environmental assets in agricultural landscapes, which generate supporting, regulating, and cultural ecosystem services, provide private benefits to the landholders. These benefits are reflected in increased property values. Ecological restoration on private land can increase both the welfare of landholders and the provision of public benefits. 


\section{Property size and extent of native vegetation matters}

Native vegetation on private land provides a range of cultural, recreational, and aesthetic amenity benefits to landholders. On rural properties, the retention of native vegetation is generally in conflict with agricultural practices used to produce food and fibre. As with any limited resource, both native vegetation and agricultural land are likely to exhibit diminishing marginal values. This means that the value of the last hectare of land is lower than the value of the second last hectare. There could be an optimal combination of native vegetation and agricultural land on private rural property that maximises the total benefit a landholder derives from the property, which would be reflected in a higher property value. The optimal combination of these land uses depends on the landholder's goals and preferences (see Chapter 13). It is likely that the value of native vegetation varies across the spectrum of landholders, such as full-time farmers, parttime farmers, and lifestyle farmers. For example, owners of lifestyle properties have relatively strong preferences for amenity values of native vegetation, while owners of large agricultural properties have preference for the production value of agricultural land.

Polyakov et al. (2015) used data from around 7,500 rural properties in north central Victoria sold between 1990 and 2011 to estimate the value that a variety of rural landholders place on native vegetation on their properties. They used property size as a proxy for landholder type to model differences in the values of native vegetation across the range of property types in a multifunctional rural landscape. They found that the value of native vegetation is smaller on larger properties, which are associated with production-oriented farmers, and larger on smaller properties, which are associated with lifestyle landholders. The value of additional native vegetation is higher on the properties which currently have little native vegetation, and decreases with greater areas of native vegetation. This implies that increasing the area of native vegetation on a property increases its value up to an optimal point (see Figure 14.2), after which additional native vegetation decreases the property value. The proportion of native vegetation that maximises the property value, as well as the extent to which it increases the property value, varies across property sizes (see Figure 14.2). This reflects landholders' targets and priorities. For example, a 1 hectare property would reach 
its highest value when native vegetation covers about 45 per cent of its area. Such a property would be worth approximately 25 per cent more than a similar property without any native vegetation. Further increase of the area of native vegetation would decrease the property value relative to the optimum, and when the proportion of native vegetation exceeds 90 per cent of the property area, its value becomes lower than the value of similar property without any native vegetation. As the property size increases, the optimal proportion of native vegetation becomes lower and native vegetation has a smaller impact on property values. The optimal proportions of native vegetation for 10 hectare, 100 hectare, and 1,000 hectare properties are estimated to be 37 per cent, 29 per cent, and 20 per cent, respectively. These proportions would increase property values by, respectively, 16 per cent, 9 per cent, and 5 per cent relative to the values of similar properties without any native vegetation. Adding more native vegetation after reaching these optimal proportions would decrease property values: after proportions of native vegetation reach 64 per cent, 58 per cent, and 40 per cent, respectively, values of these properties would become lower than the values of similar, fully cleared properties.

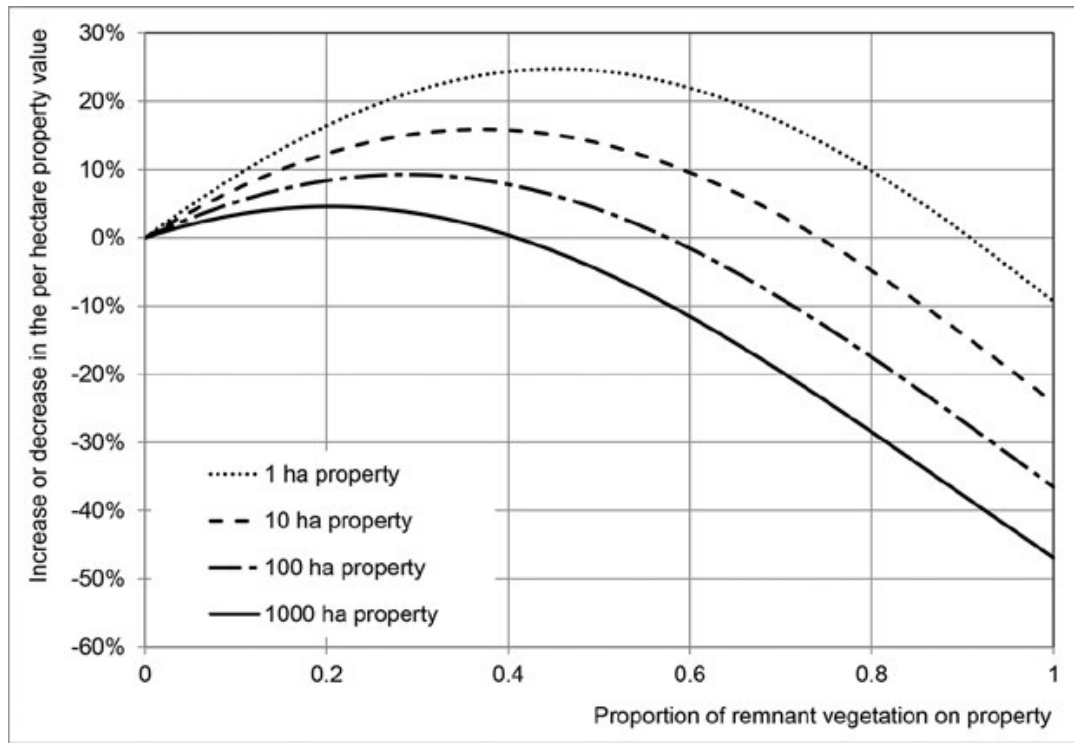

Figure 14.2: Effect of the proportion of native vegetation on land value by property size over time.

Source: Maksym Polyakov, David J. Pannell, Ram Pandit, Sorada Tapsuwan, Geoff Park, 'Capitalized Amenity Value of Native Vegetation in a Multifunctional Rural Landscape', American Journal of Agricultural Economics, 2014, 97(1): 299-314, by permission of 


\section{It is important to account for private benefits when planning ecological restoration}

A large proportion of the costs of ecological restoration projects consist of opportunity costs, which in this context is the loss of income that occurs when land use is changed from agriculture or other productive use to conservation. Traditionally, opportunity costs of ecological restoration in agricultural landscapes have been accounted for using land values (Westphal et al. 2007) or the capitalised revenue of agricultural production (Crossman and Bryan 2006). The latter is aggregated present value of future net income from the land, which should approximately match the land's sale value if the only values that matter are commercial values. Using these values to represent the opportunity cost of restoration implies that when a parcel of land is acquired for an ecological restoration project, the landholder loses all private benefits generated by this parcel. However, when ecological restoration is conducted on private land with the landholder retaining ownership of the land, the landholder captures the benefits generated by the restored ecosystem, such as amenity from native vegetation. This reduces the opportunity cost and overall cost of the restoration project. Furthermore, because the value of privately captured benefits of ecosystem services varies with property type, size, and the amount of existing native vegetation on the property (see Figure 14.2), the opportunity costs of ecological restoration would be lower on smaller properties and properties with little native vegetation. Ignoring private benefits in calculation of opportunity costs of ecological restoration on private lands could lead to misleading recommendations for ecological restoration planning.

In a study of Mt Alexander Shire in Victoria, Polyakov and Pannell (2014) tested whether ignoring private benefits in calculating the opportunity cost resulted in different optimal (from the point of view of maximising public benefits) spatial allocation of ecological restoration and different biodiversity outcomes. They compared optimal ecological restoration strategies resulting from two different assumptions about opportunity cost. In one scenario, opportunity cost was based on the land value, while in another scenario, opportunity cost was estimated by taking into account the land value and private 
benefits of native vegetation. The scenario accounting for private benefits of ecological restoration gave a substantially (up to 75 per cent) better biodiversity outcome than the scenario using opportunity cost based on only land values. The spatial pattern of ecological restoration in these scenarios differed substantially. In the scenario that uses land values for opportunity cost, ecological restoration is selected on larger properties, which have lower per hectare land values. In the scenario that takes into account private benefits of native vegetation, ecological restoration takes place on smaller properties (lifestyle landholders). The land value of these properties is higher, but converting part of the property to native vegetation does not decrease property value. As a result, allocation of ecological restoration shifts towards smaller properties, even though transaction costs and overhead costs of implementing smaller ecological restoration projects are higher. This outcome is consistent with the findings of Race et al. (2010) that lifestyle landholders and part-time farmers undertake a considerable amount of work to revegetate and enhance native vegetation.

These results show that in order to avoid providing misleading recommendations to environmental managers, it is important to take into account amenity values of native vegetation and variable opportunity cost when prioritising ecological restoration. This is especially important in multifunctional landscapes with heterogeneous landholders.

\section{Conclusion}

This chapter summarises lessons from recent studies of the private benefits of environmental assets in rural landscapes, in the context of ecological restoration. Ecosystem services of the environmental assets, such as native vegetation on private lands, generate private benefits that are captured by the landholders. The value of private benefits generated by an extra hectare of native vegetation depends on the property type and area of native vegetation currently on the property. This information on private benefits from restoration is relevant to the decisions about the targeting of ecological restoration because private benefits of ecological restoration can reduce the public cost. Specifically, landholders with high marginal private benefits of revegetation would be more willing to participate in revegetation 
programs. Targeting those landholders would provide better value for money because the program could be implemented at lower cost and with higher probability of success. Accounting for private benefits in planning and targeting restoration would result in restoration programs delivering greater benefits.

\section{Acknowledgements}

This research was conducted with the support of funding from the Australian Research Council Centre of Excellence for Environmental Decisions and the Australian National Environmental Research Program's Environmental Decisions Hub.

\section{References}

Blackmore, L. and G.J. Doole (2013) 'Drivers of landholder participation in tender programs for Australian biodiversity conservation', Environmental Science and Policy 33: 143-53.

Crossman, N.D. and B.A. Bryan (2006) 'Systematic landscape restoration using integer programming', Biological Conservation, 128: 369-83.

Ma, S. and S.M. Swinton (2011) 'Valuation of ecosystem services from rural landscapes using agricultural land prices', Ecological Economics 70: 1649-59.

Pannell, D.J. (2008) 'Public benefits, private benefits, and policy mechanism choice for land-use change for environmental benefits', Land Economics 84: 225-40.

Polyakov, M. and D.J. Pannell (2014) 'Accounting for private benefits in ecological restoration planning', presentation to Agricultural and Applied Economics Association 2014 Annual Meeting, July 27-29, Minneapolis, Minnesota.

Polyakov, M., D.J. Pannell, R. Pandit, S. Tapsuwan and G. Park (2013) 'Valuing environmental assets on rural lifestyle properties', Agricultural and Resource Economics Review 42: 159-75. 
Polyakov, M., D.J. Pannell, R. Pandit, S. Tapsuwan and G. Park (2015) 'Capitalized amenity value of native vegetation in a multifunctional rural landscape', American Journal of Agricultural Economics 97: 299-314.

Race, D., R. Sample, A. Curtis and S. McDonald (2010) Management of native vegetation on private land: Perspectives of landholders and NRM program managers in northern Victoria, a report to Landscape Logic, Commonwealth Environmental Research Program, Canberra.

Walpole, S.C. and M. Lockwood (1999) 'Influence of remnant native vegetation on rural land values: A hedonic pricing application', presentation to the Australian and New Zealand Agricultural and Resource Societies 1999 Joint Conference, Christchurch, New Zealand.

Westphal, M.I., S.A. Field and H.P. Possingham (2007) 'Optimizing landscape configuration: A case study of woodland birds in the Mount Lofty Ranges, South Australia', Landscape and Urban Planning 81: 56-66. 
This text is taken from Learning from agri-environment schemes in Australia: Investing in biodiversity and other ecosystem services on farms, edited by Dean Ansell, Fiona Gibson and David Salt, published 2016 by ANU Press, The Australian National University, Canberra, Australia. 